\title{
O MANIFESTO DA LITERATURA MARGINAL: O TEXTO “TERRORISMO LITERÁRIO”, DE FERRÉZ, E O PODER DE DESVENDAMENTO DO MUNDO E DO MOVIMENTO ARTÍSTICO DA LITERATURA PERIFÉRICA
}

\section{THE MANIFESTO OF THE MARGINAL LITERATURE: THE TEXT “LITERARY TERRORISM” BY FERRÉZ, AND THE POWER OF UNVEILING OF THE WORLD AND OF ARTISTIC MOVEMENT OF THE PERIPHERAL LITERATURE}

\author{
Bianca do Rocio Vogler" \\ Prof. Dr. Miguel Sanches Neto**
}

Resumo: A proposta desse artigo é a de analisar o texto "Terrorismo literário", de Ferréz, que integra o livro Literatura marginal: talentos da escrita periférica (2005), e se caracteriza pelo que poderíamos chamar de um "Manifesto da Literatura Marginal", se estabelecendo com um sentido de desvendamento e de protesto perante fatores que permeiam a vida social e literária. Essa identificação relacionase com os textos modernistas "Manifesto da Poesia Pau-Brasil" (1924) e "Manifesto Antropófago" (1928), de Oswald de Andrade, destacando uma importância desse período da Literatura Brasileira na conquista de espaço no cenário artístico nacional pela Literatura Marginal. Para a realização da análise pretendida, considerouse necessário, ainda, fazer uso de textos teóricos que embasam essa questão do engajamento na literatura. Tais textos são as obras Que é a literatura? (1993), de

\footnotetext{
* Graduação no curso Licenciatura em Letras-Português/Inglês pela Universidade Estadual de Ponta Grossa (UEPG). Mestranda do programa de Mestrado em Linguagem, Identidade e Subjetividade, da Universidade Estadual de Ponta Grossa (UEPG). E-mail: biavogler@gmail.com

** Graduação em Letras pela FAFIMAN (1984-1986), especializou-se em Literatura Brasileira na Pontifícia Universidade Católica do Paraná, em Curitiba 1989. Cursou o mestrado em Teoria Literária na Universidade Federal de Santa Catarina (1990-1992). É doutor em Letras pela Unicamp (1994-1998) e professor-associado de literatura brasileira na Universidade Estadual de Ponta Grossa. Foi Diretor-Presidente da Imprensa Oficial do Estado do Paraná (1999-2002), Pró-Reitor de Pesquisa e Pós-graduação (2003) e Pró-Reitor de Extensão e Assuntos Culturais da UEPG (2006-2010). Tem publicado artigos, ensaios e livros sobre autores nacionais, entre eles Manoel de Barros, Dalton Trevisan e Cecília Meireles. Suas áreas de atuação universitária são: literatura brasileira (do romantismo à contemporaneidade); formação do leitor literário; crítica literária; revistas literárias. E-mail: msn@interponta.com.br
} 
Jean-Paul Sartre, O grau zero da escritura (1971), de Roland Barthes, e Pode o subalterno falar?, de Gayatri Chakravorty Spivak.

Palavras-chave: “Terrorismo literário”. Literatura Marginal. Movimento Modernista Brasileiro.

\begin{abstract}
The purpose of this article is to analyze the text "Literary terrorism" by Ferréz, integrating of the book Marginal Literature: talents of peripheral writing (2005), and is characterized by what might be called a "Manifesto of Marginal Literature", establishing a sense of revelation and protest against factors that permeate the social and literary life. This identification relates to the modernist texts "Manifesto of Pau-Brazil Poetry" (1924) and "Anthropophagous Manifesto" (1928), Oswald de Andrade, highlighting importance of this period of Brazilian Literature in the conquest of space on the national art scene by Marginal Literature. To perform the required analysis, it was considered necessary also make use of theoretical texts that underpin this issue engagement in literature. Such texts are works What is literature? (1993), Jean-Paul Sartre, Writing degree zero (1971), Roland Barthes, and Can the subaltern speak?, Gayatri Chakravorty Spivak.
\end{abstract}

Keywords: "Literary terrorism”. Marginal Literature. Brazilian Modernist Movement.

Uma sociedade justa pressupõe o respeito dos direitos humanos, e a fruição da arte e da literatura em todas as modalidades e em todos os níveis é um direito inalienável.

(Antonio Candido, O direito à literatura).

\section{INTRODUÇÃO}

O reconhecimento de que a arte configura-se como um dos principais meios para que as pessoas obtenham a percepção dos problemas que permeiam sua sociedade tem possibilitado, nos últimos tempos, um engajamento muito maior por parte dos artistas em suas criações. Isso ocorre por haver nesses cidadãos um certo sentimento de dever a que eles se veem impelidos, já que se caracterizam como figuras detentoras de um grande poder de influência e persuasão sobre as opiniões dos demais indivíduos.

Nesse processo, ao partirem de uma visão de mundo que lhes possibilita construírem obras em que a realidade é exposta cada vez mais sem velamentos, em sua forma mais crua e realista, esses artistas acabam por apresentar suas críticas às condições sociais e morais predominantes. Assumem, assim, uma posição diante dos conflitos existentes em sua sociedade, colocando-se na linha de frente dos embates gerados pelos mesmos e instaurando ecos de suas vozes nas vozes daqueles que os ratificam.

Por meio desse movimento de posicionamento, a partir do qual pode se erigir uma conquista gradual de espaço, foi que se possibilitou que obras de artistas postos à margem da sociedade fossem, pouco a pouco e cada vez mais, reconhecidas como arte com um valor artístico real. E essa é 
uma conquista que vai muito além da forma como esses trabalhos eram vistos no início (e como ainda são vistos em muitos casos), como simples veiculadores de um senso de função social de desvendamento do mundo.

É claro que tal função possui uma enorme importância no exame dessas obras, no entanto, essa conquista de espaço no cenário artístico se apresenta como uma grande evolução na luta desses artistas, pois se veem tendo seu talento analisado. Isso se evidencia não só no crescimento das publicações e da visibilidade de seus trabalhos, mas também no aumento de textos teóricos em que se focam as questões do engajamento e do desvendamento de mundo em que a arte deve estar empenhada, os quais ressaltam o aspecto do valor artístico além da função social.

No Brasil, muito vem se trabalhando para que autores da Literatura Marginal ou Periférica conquistem seu lugar na Literatura Nacional. Alguns dos trabalhos de grande relevância nessa direção são as edições especiais sobre Literatura Marginal, lançadas pela revista Caros Amigos e intituladas "Caros Amigos/Literatura Marginal: a cultura da periferia", as quais tiveram sua publicação nos anos de 2001, 2002 e 2004, reunindo 48 autores. Partindo dessas edições, a união entre a revista Caros Amigos e o escritor paulista Ferréz, um dos nomes principais desse gênero literário, resultou, também, em um livro denominado Literatura marginal: talentos da escrita periférica (2005), em que foram reunidos textos de vários autores da Literatura Marginal.
E é possível observar, no texto que abre esse livro, a construção que Ferréz realiza em uma espécie de "ataque" ao preconceito e às barreiras de que a literatura esteve sempre revestida. Nada mais natural que o título desse texto fosse "Terrorismo literário", já que é uma tentativa de desconstruir essas barreiras que impedem os escritores marginalizados de exporem suas obras, uma busca para que eles não precisem mais de intermediários para estar presentes em um texto de ficção.

\section{O PONTAPÉ INICIAL: O MOVIMENTO Modernista Brasileiro}

Mas antes dessas ações e de todos os movimentos voltados ao reconhecimento da Literatura Marginal, vê-se como fundamental para que se pudesse chegar a esse momento da história literária brasileira, as lutas de vários artistas ao longo do tempo para que a identidade nacional fosse considerada de primordial relevância nas produções artísticas do país. E o movimento a ser aqui observado é o do Modernismo, que teve grande importância para o engajamento social presente nos movimentos literários posteriores.

Assim, um dos eventos mais famosos da Literatura Brasileira, bem como das artes nacionais em geral, foi a conhecida "Semana de Arte Moderna de 1922". Ocorrida em São Paulo, no início do século XX, era uma busca por mudanças no cenário artístico nacional por meio do choque. Como um evento concentrado em três dias de exposições, palestras, declamações e apresentações musicais, 
um caráter de radicalidade e quebra foi o que possibilitou o estabelecimento de uma importância fundamental do acontecimento para a história do país.

A partir desse fato, os artistas passaram a buscar de forma mais evidente a apreensão de um sentido de nacionalidade para suas composições. E esse sentido de nacionalidade estava, e muito, ligado aos fatores sociais formadores da nação, as diferenças culturais regionais, as opressões sofridas pelos indivíduos nas diversas regiões do país, os cidadãos habitantes das localidades periféricas esquecidas do Brasil.

$E$ nessa perseguição por uma brasilidade, alguns desses artistas desenvolveram, além de atos artísticos, ações revolucionárias visando o estabelecimento de certas condutas para que se pudesse chegar ao objetivo almejado. Alguns desses atos são o "Manifesto da Poesia Pau-Brasil" (1924) e o "Manifesto Antropófago" (1928), elaborados pelo poeta e romancista Oswald de Andrade, uma das principais figuras do Modernismo brasileiro.

O primeiro, lançado pelo jornal Correio da Manhã em 18 de março de 1924, procurava instituir critérios (ou, na verdade, desconstruir os critérios vigentes até o momento) para a criação poética. Para isso, Oswald de Andrade expõe o caráter nacionalista do Movimento Modernista, pregando a ruptura com as influências europeias que sempre estiveram presentes na Literatura Brasileira.

Nenhuma fórmula para a contemporânea expressão do mundo. Ver com olhos livres.
[...]

O estado de inocência substituindo o estado de graça que pode ser uma atitude do espírito. O contrapeso da originalidade nativa para inutilizar a adesão acadêmica.

A reação contra todas as indigestões de sabedoria. O melhor de nossa tradição lírica. O melhor de nossa demonstração moderna.

Apenas brasileiros de nossa época. $\mathrm{O}$ necessário de química, de mecânica, de economia e de balística. Tudo digerido. Sem meeting cultural. Práticos. Experimentais. Poetas. Sem reminiscências livrescas. Sem comparações de apoio. Sem pesquisa etimológica. Sem ontologia.

Bárbaros, crédulos, pitorescos e meigos. Leitores de jornais. PauBrasil. A floresta e a escola. O Museu Nacional. A cozinha, o minério e a dança. A vegetação. Pau-Brasil. (ANDRADE, 1924, p. 3-4).

Já no segundo manifesto, lançado no primeiro número da Revista de Antropofagia, em março de 1928, tem-se um olhar mais filosófico, em que Oswald de Andrade critica o comportamento em geral dos brasileiros, apontando para o que poderíamos denominar como uma "importação dos valores europeus". Assim, o poeta se revolta contra toda essa "imitação tupiniquim da cultura europeia", propondo que tais valores sejam deglutidos e transformados.

Contra todos os importadores de consciência enlatada. A experiência palpável da vida. E a mentalidade pré-lógica para o Sr. Lévy-Bruhl estudar. Queremos a Revolução Caraíba. 
Maior que a Revolução Francesa. A unificação de todas as revoltas eficazes na direção do homem. Sem nós a Europa não teria sequer a sua pobre declaração dos direitos do homem.

A idade de ouro anunciada pela América. A idade de ouro. E todas as girls. (ANDRADE, 1928, p. 2).

Dessa forma, vemos que esses manifestos modernistas tiveram grande importância não só para aquele momento histórico da Literatura Brasileira, mas também para os movimentos artísticos posteriores que foram possibilitados e incentivados pelo Modernismo. A radicalidade do evento do início do século $\mathrm{XX}$ tornou-se essencial preparador dos movimentos seguintes, pois apresentava possibilidades de ruptura total com os valores anteriores e construção de novos ideais, os quais tinham como objetivo principal a conquista de voz por parte de todos os indivíduos.

\section{O Manifesto da Literatura Marginal}

Assim, um desses movimentos possibilitados pelas lutas modernistas é o da Literatura Marginal, que tem crescido nos últimos anos e se tornado cada vez mais visível por meio de atitudes de diversos incentivadores. Essa literatura caracteriza-se por ser composta tanto de escritores que tematizam as questões vivenciadas pelos indivíduos que estão em uma posição identificada como à margem da sociedade quanto de escritores que se encontram nessa própria posição. Essa última característica só vem sendo praticada e reconhecida em uma maior medida muito recentemente. Por isso, ape- sar de começar a conquistar seu espaço na Literatura Nacional, esses cidadãos continuam enfrentando barreiras e preconceitos que estão arraigados à nossa sociedade.

Dessa maneira, observando esses textos deparamos com uma característica predominante, intensa e, analisando que o que se busca é um impacto e uma reflexão maiores, necessária: a agressividade. Tal característica pode ser percebida nas imagens criadas, nas linguagens utilizadas, em uma noção de realidade percebida nessas criações, entre outros pontos em que se identifica a presença desse ponto chave da Literatura Marginal.

E, então, consideramos essa agressividade como necessária por ser esse o caráter preponderante nas vidas desses indivíduos, em suas convivências com o mundo, pois, estando à margem do centro, esses sujeitos são expostos a situações em que se evidencia a violência aos seus direitos como cidadãos.

Portanto, observa-se que a Literatura Marginal se utiliza de um dos recursos grandemente utilizados pelos artistas modernistas em seu movimento, já que um dos objetivos do Modernismo era causar o choque para que se conseguisse uma repercussão de seus atos. Isso é bastante evidente nos dois manifestos escritos por Oswald de Andrade, sendo que faz uso de ideias de certa forma radicais e exacerbadas.

E é essa espécie de choque, radicalidade e exacerbação que podemos identificar em "Terrorismo literário", texto de abertura do livro Literatura marginal: talentos da escrita periférica (2005). Nesse texto, Ferréz compõe uma investida contra 
os valores tradicionalistas e excludentes que constituem a literatura desde sempre. Assim, a representação desse escrito é fundamental para que esses cidadãos marginalizados possam tomar seus lugares como escritores diante de uma sociedade repleta de preconceitos e fronteiras tidas como intransponíveis.

Já no início do texto, o escritor fala de uma troca de instrumento de luta, da capoeira, anteriormente usada pelos escravos para lutar contra seus donos e feitores, muda-se para as palavras, que agora são o auxílio utilizado na luta contra os seus opressores:

A capoeira não vem mais, agora reagimos com a palavra, porque pouca coisa mudou, principalmente para nós.

Não somos movimento, não somos os novos, não somos nada, nem pobres, porque pobre, segundo os poetas da rua, é quem não tem as coisas.

Cala a boca, negro e pobre aqui não tem vez! Cala a boca!

Cala a boca uma porra, agora a gente fala, agora a gente canta, e na moral agora a gente escreve. (FERRÉZ, 2005, p. 9).

Percebe-se, nesse fragmento, a agressividade sendo empregada como um meio de chamar a atenção para os fatos e de expor todo um sentimento de indignação perante as configurações históricas e sociais prevalecentes no Brasil. E é essa característica que predominará em todo o texto, estabelecendo as reais condições que formam a sociedade brasileira em detrimento de uma igualdade de direitos inexpressiva.

Logo em sua afirmação seguinte, Ferréz indica, então, um fato de extrema relevância para a caracterização dos objetivos da literatura: a tomada de posição, a adesão a um ideal, a busca por esse ideal em suas obras, enfim, o engajamento.

Quem inventou o barato não separou entre literatura boa/feita com caneta de ouro e literatura ruim/escrita com carvão, a regra é só uma, mostrar as caras. Não somos o retrato, pelo contrário, mudamos o foco e tiramos nós mesmos a nossa foto. (FERRÉZ, 2005, p. 9, grifo nosso).

Tal aspecto de engajamento é o centro de alguns dos trabalhos teóricos e filosóficos de grandes estudiosos da Literatura, da Linguagem e da Sociedade, tendo em diversas visões suas diferentes formas de abordagem e distintas caracterizações, apesar de possuírem um mesmo fim.

Um dos maiores estudiosos que pode ser citado é o filósofo francês Jean-Paul Sartre, o qual, em seu livro Que é a literatu$r a$ ? (1993), desenvolve o tema da necessidade de que a literatura esteja sempre engajada na busca por resoluções dos problemas que afetam a sociedade, tendo um olhar bastante político dessa arte e demonstrando uma intenção que poderíamos identificar até mesmo como panfletária para tal gênero artístico. No entanto, o filósofo foca essa sua visão sobre a composição literária na questão da prosa, distinguindo-a da poesia e das outras formas de arte e identificando-a como o lugar reservado para a luta social.

Em Sartre, então, essa característica do engajamento a que os escritores prosadores devem se associar é o que os diferencia dos poetas e dos demais artistas, pois, considerando a prosa como um lugar de ação e não apenas de realização da arte pela 
arte, o filósofo francês empreende uma divisão de objetivos existentes entre as artes.

A prosa, para Sartre, é, assim, o falar, e:

Falar é agir; uma coisa nomeada não é mais inteiramente a mesma, perdeu a sua inocência. Nomeando a conduta de um indivíduo, nós a revelamos a ele; ele se vê. [...] ao falar, desvendo a situação por meu próprio projeto de mudá-la; desvendo-a a mim mesmo e aos outros, para mudá-la; atinjo-a em pleno coração, traspasso-a e fixo-a sob todos os olhares; passo a dispor dela; a cada palavra que digo, engajo-me um pouco mais no mundo e, ao mesmo tempo, passo a emergir dele um pouco mais, já que o ultrapasso na direção do porvir. Assim, o prosador é um homem que escolheu determinado modo de ação secundária, que se poderia chamar de ação por desvendamento. [...] o escritor "engajado" sabe que a palavra é ação: sabe que desvendar é mudar e que não se pode desvendar senão tencionando mudar. (SARTRE, 1993, p. 20).

Fica visível nessa descriçãoestabelecida pelo filósofo francês a respeito do escritor de prosa o caráter que identificamos no texto de Ferréz, pois o escritor paulista deixa uma posição clara e se expressa de forma a revelar as desigualdades existentes entre os indivíduos. Para apresentar a Literatura Marginal, seus objetivos e os indivíduos que a integram, ele se posiciona contra a ordem estabelecida, já que essa ordem é de exclusão, segregação e hierarquização.

Seguindo esse posicionamento de estabelecer a prosa como o espaço para o engajamento, Sartre pondera, ainda, sobre sua visão a respeito do que seria um escritor engajado, esclarecendo uma função fundamental de mediação a que este estaria destinado quando assume sua posição nesse processo, pois está sempre expondo ideias a partir de um ponto de vista para que aqueles que o leem reflitam e ponderem para aderirem ou não a elas:

Eu diria que um escritor é engajado quando trata de tomar a mais lúcida e integral consciência de ter embarcado, isto é, quando faz o engajamento passar, para si e para os outros, da espontaneidade imediata ao plano refletido. $\mathrm{O}$ escritor é mediador por excelência, e o seu engajamento é a mediação. (SARTRE, 1993, p. 61-62).

Podemos dizer que Ferréz realiza esse processo de mediação se utilizando de sua linguagem, das linguagens desses excluídos, uma linguagem escrita possuidora de uma aproximação muito profunda com a linguagem falada. E aí está, então, "A própria linguagem margeando e não os da margem, marginalizando e não os marginalizados, rocha na areia do capitalismo." (FERRÉZ, 2005, p. 9), pois é por meio dela que o mundo desses indivíduos será desvendado em sua real forma. É a linguagem que trabalha para que sejam apresentadas as divergências sociais, e é por meio da evidenciação das diversidades de linguagens que esses escritores conseguem constituir suas literaturas engajadas, estando, dessa maneira, em consonância com aquilo que é produzido pela própria realidade. 
E temos muito a proteger e a mostrar, temos nosso próprio vocabulário que é muito precioso, principalmente num país colonizado até os dias de hoje, onde a maioria não tem representatividade cultural e social, na real, nego, o povo num tem nem o básico pra comer, e mesmo assim, meu tio, a gente faz por onde ter us barato pra aguentar mais um dia. (FERRÉZ, 2005, p. 11).

Nesse sentido, no momento em que nos deparamos com a linguagem e sua importância no movimento de ascensão da Literatura Marginal, tem-se a possibilidade de voltar-se para o estudo o grau zero da escritura (1971), do filósofo e semiólogo francês Roland Barthes, em que há o desenvolvimento da questão da linguagem como reflexo da sociedade, ou seja, a escolha de uma dada linguagem pelo escritor o coloca em uma dada posição em relação às configurações da sua sociedade. Em seu estudo, Barthes aborda um aspecto da escrita que considera o primordial na apreensão desse engajamento pelo escritor: a escritura. Ele aponta, assim, para o sentido de posicionamento que é incrustada na composição de um escritor ao fazer sua escolha de uma determinada escritura. Diz, então, que “[...] a escritura a que me confio já é toda ela instituição; ela descobre meu passado e minha escolha, dá-me uma história, alardeia minha situação, engaja-me sem que eu tenha que dizê-lo." (BARTHES, 1971, p. 38).

[...] a escritura é uma função: é a relação entre a criação e a sociedade, é a linguagem literária transformada por sua destinação social, é a forma apreendida na sua intenção humana e ligada assim às grandes crises da História. (BARTHES, 1971, p. 23).

Portanto, se a linguagem é o centro desse processo de desvendamento, Barthes aponta para a importância que o processo de aquisição das características da linguagem falada pela linguagem escrita empreendeu no engajamento da literatura. Nesse movimento está presente uma enorme revolução para a arte, porque ela passa a ter uma percepção e apreensão mais completa da realidade.

Nesses momentos em que o escritor acompanha as linguagens realmente faladas, não mais a título pitoresco, mas como objetos essenciais que esgotam todo o conteúdo da sociedade, a escritura toma como lugar de seus reflexos a fala real dos homens; a literatura não é mais orgulho ou refúgio, começa a tornar-se um ato lúcido de informação, como se devesse primeiro aprender, reproduzindo-o, o pormenor da disparidade social; ela se propõe dar conta imediatamente, antes de qualquer outra mensagem, da situação dos homens murados na língua de sua classe, de sua região, de sua profissão, de sua hereditariedade ou de sua história. (BARTHES, 1971, p. 98).

E essa relação indissociável entre a apreensão de uma linguagem em concordância com a realidade e a representação da sociedade a que o filósofo e semiólogo francês se refere apresenta-se como o aspecto essencial na expressão dos escritores da Literatura Marginal.

Assim, em "Terrorismo literário", Ferréz identifica as desigualdades sociais 
por todo o texto, deixando evidente que sua busca por espaço se dá por um desejo de melhorar as condições de vida desses cidadãos colocados à margem, desmistificando até mesmo o discurso corrente da igualdade.

O sonho não é seguir o padrão, não é ser o empregado que virou o patrão, não, isso não, aqui ninguém quer humilhar, pagar migalhas nem pensar, nós sabemos a dor por recebê-las.

Somos o contra sua opinião, não viveremos ou morreremos se não tivermos o selo da aceitação, na verdade tudo vai continuar, muitos querendo ou não.

Um dia a chama capitalista fez mal a nossos avós, agora faz mal a nossos pais e no futuro vai fazer a nossos filhos, o ideal é mudar a fita, quebrar o ciclo da mentira dos "direitos iguais", da farsa do "todos são livres", a gente sabe que não é assim, vivemos isso nas ruas, sob os olhares dos novos capitães do mato, policiais que são pagos para nos lembrar que somos classificados por três letras classes: C,D,E. Literatura de rua com sentido, sim, com um princípio, sim, e com um ideal, sim, trazer melhoras para o povo que constrói esse país mas não recebe sua parte. (FERRÉZ, 2005, p. 9-10).

Em tal ideia exposta pelo escritor paulista, observamos que é assinalada uma espécie de reconhecimento de um limite que se pode ser alcançado, pois acredita que os preconceitos sempre estarão presentes, marcando as diferenças e as excluindo. Assim, esse processo deve ser contínuo para que possa ter efeitos, já que é um movimen- to extremamente lento por causa do preconceito que se constituiu ao longo do tempo.

Nessa perspectiva, também é possível relacionar o que Ferréz diz e a forma como se posiciona com o modo como Barthes identifica o caráter existente na escritura, dizendo que:

[...] a reflexão do escritor sobre o uso social da forma e a escolha que ele assume. [...] a moral da forma, a escolha da área social no seio da qual o escritor decide situar a Natureza de sua linguagem. [...] não se trata de escolher o grupo social para que escreve [...]. Sua escolha é uma escolha de consciência, não de eficácia. Sua escritura constitui uma maneira de pensar a Literatura, não de difundi-la. [...] a escritura é uma realidade ambígua: de um lado, nasce incontestavelmente de uma confrontação do escritor com a sociedade; de outro lado, por uma espécie de transferência mágica, ela remete o escritor, dessa finalidade social, para as fontes instrumentais de sua criação. (BARTHES, 1971, p. 24-25).

Dessa forma, seguindo essa característica de "confrontação do escritor com a sociedade" a partir da qual a escritura nasce, temos a possibilidade, ainda, de examinar a maneira como a questão da problemática da palavra como ação e da necessidade de se facultar a voz aos excluídos é analisada pela teórica indiana Gayatri Chakravorty Spivak em seu texto Pode o subalterno falar? (2010).

Nessa obra, Spivak desenvolve sua teoria referindo-se aos estudos de dois grandes filósofos franceses, Michel Foucault e Gilles Deleuze, os quais abordam a questão da 
representação, da necessidade de os intelectuais do Primeiro Mundo tomarem parte nos discursos dos sujeitos do Terceiro Mundo. Para Spivak, essas ideias são equivocadas, pois "[...] ambos os autores ignoram sistematicamente a questão da ideologia e seu próprio envolvimento na história intelectual e econômica." (SPIVAK, 2010, p. 22).

A autora reconhece um valor presente nas teorias desses filósofos, mas indica os pontos em que suas visões estão equivocadas:

Foucault está certo ao sugerir que tornar visível o que não é visto pode também significar uma mudança de nível, dirigindo-se a uma camada de material que, até então, não tinha tido pertinência alguma para a história e que não havia sido reconhecida como tendo qualquer valor moral, estético ou histórico.

É o deslize entre tornar o mecanismo visível e tornar o indivíduo vocal, evitando, em ambos os casos, "qualquer forma de análise [do sujeito], quer seja psicológica, psicanalítica ou linguística", que é consistentemente problemático (PK, p. 49-50). (SPIVAK, 2010, p. 61).

Por isso, a teórica indiana constrói sua tese no sentido de que se deve pensar tais representações, pois estão repletas de influências de um contexto diverso daquele que é representado, o que pode resultar em uma estereotipagem e no esquecimento de que "[...] o sujeito subalterno colonizado é irremediavelmente heterogêneo." (SPIVAK, 2010, p. 57). Isso porque esse processo de representação muitas vezes acaba por criar o que Spivak denomina como "violência epistêmica”, que é essa pretensão de falar em nome do excluído, mas que muitas vezes na verdade também resulta na instauração de um fenômeno excludente, praticando, desse modo, o mesmo erro que se comprometia a denunciar.

Então, a teórica aponta para o problema que será a base de sua investigação:

Para o "verdadeiro" grupo subalterno, cuja identidade é a sua diferença, pode-se afirmar que não há nenhum sujeito subalterno irrepresentável que possa saber e falar por si mesmo. A solução do intelectual não é a de se abster da representação. O problema é que o itinerário do sujeito não foi traçado de maneira a oferecer um objeto de sedução ao intelectual representante. Na linguagem um tanto arcaica do grupo indiano, a questão que se apresenta é: como podemos tocar a consciência do povo, mesmo enquanto investigamos sua política? Com que voz-consciência o subalterno pode falar? (SPIVAK, 2010, p. 60-61).

Assim, Spivak defende que o processo real seja o de possibilitar a tomada de voz por parte desses próprios sujeitos excluídos para que possam, dessa maneira, conseguir ter a percepção sobre as suas vivências, podendo expô-las, num processo de transposição das fronteiras e afirmação das suas identidades.

E é nessa direção que caminha o texto de Ferréz, assinalando a tomada de voz por parte desses indivíduos por muito tempo excluídos, oprimidos, marginalizados:

Somos mais, somos aquele que faz a cultura, falem que não somos marginais, nos tirem o pouco que sobrou, 
até o nome, já não escolhemos o sobrenome, deixamos para os donos da casa-grande escolher por nós, deixamos eles marcarem nossas peles, por que teríamos espaço para um movimento literário? Sabe duma coisa, o mais louco é que não precisamos de sua legitimação, porque não batemos na porta para alguém abrir, nós arrombamos a porta e entramos.

Sua negação não é novidade, você não entendeu? Não é o quanto vendemos, é o que falamos, não é por onde, nem como publicamos, é que sobrevivemos.

Estamos na rua, loco, estamos na favela, no campo, no bar, nos viadutos, e somos marginais mas antes somos literatura, e isso vocês podem negar, podem fechar os olhos, virarem as costas, mas, como já disse, continuaremos aqui, assim como o muro social invisível que divide esse país. (FERRÉZ, 2005, p. 10).

Em tal tomada de voz estão presentes os esforços desses cidadãos e daqueles que buscaram realizar esse movimento de vocalizar as experiências de quem está à margem.

E o processo primordial é, então, o de possibilitar que os cidadãos tenham uma visão real do mundo em que vivem e que se apossem de seu direito de falar e de expressar suas ideias, para que, dessa forma, consigam lutar pelo seu espaço na sociedade e por aquilo que lhe é de direito.

\section{REFERÊNCIAS}

ANDRADE, O. de. Manifesto antropófago. Disponível em: <http://www. faculdadesequipe.com.br/arquivos/o8eze 5 98249e17a9a7927a4e5f201b5cc6dibd7e.pdf>. Acesso em: 18 jan. 2013.

\section{Manifesto da poesia Pau-}

Brasil. Disponível em: <http://www. mariosantiago.net/Textos\%20em\%20PDF/ Manifesto\%20Pau-Brasil.pdf>. Acesso em: 18 jan. 2013.

BARTHES, R. O grau zero da escritura. Tradução de Anne Arnichand e Álvaro Lorencini. São Paulo: Cultrix, 1971.

FERRÉZ (Org.). Literatura marginal: talentos da escrita periférica. Rio de Janeiro: Agir, 2005.

SARTRE, J-P. Que é a literatura? Tradução de Carlos Felipe Moisés. 2.ed. São Paulo: Ática, 1993.

SPIVAK, G. C. Pode o subalterno falar? Tradução de Sandra Regina Goulart Almeida, Marcos Pereira Feitosa e André Pereira Feitosa. Belo Horizonte: Editora UFMG, 2010.

Recebido para publicação em 11 de abril de 2013 Aceito para publicação em 1 de nov. de 2013 